Article

\title{
Physical Activity Levels for Girls and Young Adult Women versus Boys and Young Adult Men in Spain: A Gender Gap Analysis
}

\author{
Xian Mayo ${ }^{1, *(\mathbb{D})}$, Antonio Luque-Casado ${ }^{1}\left(\mathbb{D}\right.$, Alfonso Jimenez ${ }^{1,2,3}$ and Fernando del Villar ${ }^{1}(\mathbb{C}$ \\ 1 Observatory of Healthy and Active Living of Spain Active Foundation, Centre for Sport Studies, King Juan \\ Carlos University, 28942 Madrid, Spain; antonio.luque@urjc.es (A.L.-C.); alfonso.jimenez@ingesport.es (A.J.); \\ fernando.delvillar@urjc.es (F.d.V.) \\ 2 GO Fit LAB, Ingesport, 28003 Madrid, Spain \\ 3 Advanced Wellbeing Research Centre, College of Health, Wellbeing \& Life Sciences, Sheffield Hallam \\ University, Sheffield S9 3TU, UK \\ * Correspondence: xian.mayo@urjc.es; Tel.: +34-91-488-7772
}

Received: 29 June 2020; Accepted: 31 July 2020; Published: 4 August 2020

check for updates

\begin{abstract}
Despite that the health benefits of physical activity (PA) are clear, during the last years, a noticeable plateau or slight increase in physical inactivity levels in Spanish adolescents and young adults has been reported. In addition, there seems to be a progressive reduction of the total PA performed with age in both adolescent and young women as well as adult men. We aimed to analyze these changes with age in moderate-to-vigorous physical activity (MVPA) in a sample of Spanish adolescents and young adults within the age range of $15-24$ years old $(n=7827)$, considering the gender and using the short form of the International Physical Activity Questionnaire. For that, we implemented a two-way analysis of variance (ANOVA) considering both the gender and the age group surveyed. Generally, our findings showed a reduction in the daily MVPA performed from adolescence to young adulthood in Spaniards. Within these reductions, girls reduce their PA levels at a different age and pace in adolescence and young adulthood in comparison to boys. Though girls were less active than boys in the 15-18 year age range, these differences were no longer significant at older ages. Our results point out the necessity of implementing different policy approaches based on gender (i.e., for girls and young women), since reductions in the MVPA performed occur at particular ages and paces in comparison to boys and young men. This difference indicates that the traditional approach during adolescence and young adulthood is inadequate for tackling physical inactivity without considering the population's gender.
\end{abstract}

Keywords: physical inactivity; adolescence; International Physical Activity Questionnaire (IPAQ)

\section{Introduction}

The health benefits of physically active living during adolescence include increased cardiorespiratory and muscular fitness and improved cardiometabolic health, weight status, and quality of life [1]. Research indicates that some health benefits might be carried forward into adulthood, particularly benefits related to bone health and cancer prevention [2]. In this regard, physical activity (PA) performed during adolescence somehow determines the PA performed in adult life [3,4]. This fact would suggest the necessity of promoting active lifestyles early in life [5]. Because of the unique benefits for tackling non-communicable diseases, World Health Organization member states endorsed the Global Action Plan on PA, agreeing to reduce the physical inactivity prevalence for both adolescences and adults by $15 \%$ with respect to their baseline levels by 2030 [6]. 
Despite the well-known health benefits of physical activity, the prevalence of physical inactivity has remained stable during the last decade for both adolescents [7] and adults [8]. In this regard, previous studies have reported low levels of PA and scarce improvements in the last years for adolescents in general [9], and particularly for Spanish youngsters [10]. Considering all this, and with the current trends in mind, the $15 \%$ relative reduction in physical inactivity will possibly not be met by $2030[7,8]$. On top of this lack of change, gender differences are significant, with higher prevalence in girls and women in comparison to boys and men during these ages [10].

From adolescence to adulthood, previous studies have reported that there is a progressive reduction in the total PA performed [11-13]. This change in PA performed from late adolescence to adulthood is a consequence of the intense social shift in which significant life events happen [14]. In this regard, there is a concomitant transition from structured sport to non-organized PA that may modify total PA levels, potentially affecting social and psychological health, particularly in young women [15]. In this regard, it is possible that the age-related changes of the total PA performed depend on the gender, since it has been previously reported that women have an early intellectual maturity and different paternal and social pressures [16], which may affect lifestyle decisions, such as sports participation and particular use of leisure time activities [17]. Previous studies have reported reductions in the total PA performed by age for whole samples [11-13] and for both men and women separately, depicting greater decreases in the former [18]. In older age, young adult men keep being more active than young women [18]. This difference was also found in a Spanish sample, reporting reductions with age, but with more extended reductions in men than women. After a year, more total PA was still performed by men [19].

A particular drawback of the typical analysis of the prevalence of physical inactivity between adolescents and adults is that they have different physical activity recommendations by international organizations, such as the World Health Organization (WHO) (i.e., adolescents: 60 daily minutes of physical activity; adults: 75 weekly minutes of vigorous activity, 150 weekly minutes of moderate activity, or an equivalent quantity between both) [20]. A naive interpretation of the comparison of the prevalence of physical activity would presume that while most youngsters are physically inactive during adolescence, only about one-third of the adults are so [21]. One would reckon that adolescents are less physically active than their adult counterparts, which is untrue according to the consistently observed age-related decline in total self-reported physical activity [11-13].

Thus, an analysis helping to understand how the PA behaves considering the gender from adolescence to young adulthood is paramount in realizing the noticeable periods in which reductions occur in girls and young women as a consequence of changes in lifestyle decisions related to academic responsibilities and leisure time. As a consequence of these lifestyle decisions, it is possible that girls and young women reduce their PA levels at a different age and pace in adolescence and young adulthood in comparison to boys.

If changes in total PA depend on gender, particular actions should be implemented at different ages considering the gender of the young population, and should be tailored to obtain an effective policy while reducing the physical inactivity levels during adulthood. At the same time, PA should be promoted for all ages, also considering that requirements in childhood and adolescence are more demanding regarding the total time of PA in comparison with adulthood.

Therefore, this study aims to describe the moderate-to-vigorous physical activity (MVPA) performed, considering the gender, in a sample of the Spanish population from adolescence to young adulthood between 15 and 24 years old. We hypothesized that MVPA would decline with age over the transition from adolescence to young adulthood at different paces and different ages. In this regard, the reduction would be greater in men than in women, but the MVPA performed would still be higher in men in comparison to women at older ages. 


\section{Materials and Methods}

\subsection{Participants}

A sample of young Spanish women and men between 15 and 24 years were surveyed between September and December of 2018 regarding their physical activity levels $(n=8372)$. The sampling was carried out using a simple random method with a quota system $(95 \%$ confidence intervals and maximum variability $[\mathrm{P}=\mathrm{Q}=0.5]$ ) in which age, gender, socio-economic status, and geographic distribution based on population size and density were considered. All questionnaires were conducted in person with the help of a computer in their secondary school, university, or technical college classes, or at their work offices.

\subsection{Methods}

The short version of the International Physical Activity Questionnaire (IPAQ) was used to determine the MVPA performed by those surveyed [22]. The IPAQ estimates the intensity, frequency, and duration of the PA performed in the last seven days. This information was obtained by inquiring about the days of practicing vigorous and moderate PA and walking activity, as well as their respective times in minutes during those particular days. Only MVPA was considered. As IPAQ asks for the last seven days, the averaged total MVPA for every day was calculated. Only individuals responding to one valid intensity and duration of a particular intensity (i.e., both variables with an answer different from "do not know") were considered for further analysis [23]. A final sample of $n=7827$ was considered (boys/young adult men: $n=3337 ; 42.6 \%$ ). The MVPA was considered by summing the total minutes of PA performed at vigorous and moderate intensities.

\subsection{Statistical Analysis}

To ensure data robustness, the analysis was performed by merging every two ages (e.g., 15 and 16, 17 and 18, and so on). A two-way analysis of variance (ANOVA) was implemented, considering the age group (i.e., 15-16, 17-18, 19-20, 21-22, 23-24) and the gender of the surveyed people (boys/young adult men, girls/young adult women) to compare the daily MVPA (in minutes) as the dependent variable. Pairwise comparisons were performed using unpaired t-tests with Bonferroni correction. Data are represented as means with $95 \%$ confidence intervals (95\% CI). The a priori alpha level was set at 0.05 . Statistical analyses were carried out using SPSS 19.0 (SPSS Inc., Chicago, Illinois, USA).

\section{Results}

The analysis of MVPA/day showed the main effects for age $(p<0.001)$, gender $(p=0.08)$, and an interaction between age and gender $(p<0.001)$. Descriptively, the main effect of age showed reductions in the MPVA/day performed. Post hoc analysis showed a reduction in MVPA/day for younger ages but not for older ages. Data considering age can be observed in Table 1 . In addition, analyzing the main effect of gender, women performed slightly less MVPA/day in comparison to men (men: 46.6 min/day; women: $43.1 \mathrm{~min} /$ day).

As can be observed in Figure 1, the interaction between age and gender showed different reductions with older ages for men and women $(p \leq 0.01-0.001)$. Post hoc analyses showed that in men, there were no reductions between 19-20 years old and 21-22 or 23-24 years old, or between 21-22 years old and 23-24 years old $(p>0.05)$. On the other hand, post hoc analysis in women showed no differences between 15-16 and 17-18 years old, between 19-20 years and 21-22 years old, and between 21-22 years old and 23-24 years old ( $p>0.05)$. When analyzing gender differences within each age group, post hoc analyses showed significant differences between men and women in the groups of 15-16 years old ( $p<$ $0.001)$ and $17-18$ years old $(p=0.009)$. After those ages, no differences were observed $(p>0.05)$. 
Table 1. Moderate-to-vigorous physical activity (MVPA) (in minutes/day) of ages 15-24 in a sample of Spanish adolescents and young adults $(n=7827)$.

\begin{tabular}{cccc}
\hline & $\begin{array}{c}\text { Mean } \\
\text { (Minutes/Day) }\end{array}$ & $\begin{array}{c}\text { Lower 95\% CI } \\
\text { (Minutes/Day) }\end{array}$ & $\begin{array}{c}\text { Higher 95\% CI } \\
\text { (Minutes/Day) }\end{array}$ \\
\hline Ages (years) & & \\
\hline 15-16 years old $(\mathrm{n}=2194)$ & 64.7 & 62.5 & 66.9 \\
\hline 17-18 years old $(\mathrm{n}=1618)$ & $57.7^{*}$ & 55.1 & 60.2 \\
\hline 19-20 years old $(\mathrm{n}=1869)$ & $37.4^{*, \#}$ & 35.2 & 40.1 \\
\hline 21-22 years old $(\mathrm{n}=1462)$ & $34.8^{*, \#}$ & 32.1 & 37.6 \\
\hline 23-24 years old $(\mathrm{n}=684)$ & $29.5^{*}, \#, \%$ & 25.5 & 33.5 \\
\hline
\end{tabular}

Data are means $\pm 95 \%$ confidence interval $(\mathrm{CI}){ }^{*}$ : Significantly lower than the $15-16$ year group. \#: Significantly lower than the 17-18 year group. ${ }^{\%}$ : Significantly lower than the 19-20 year group.

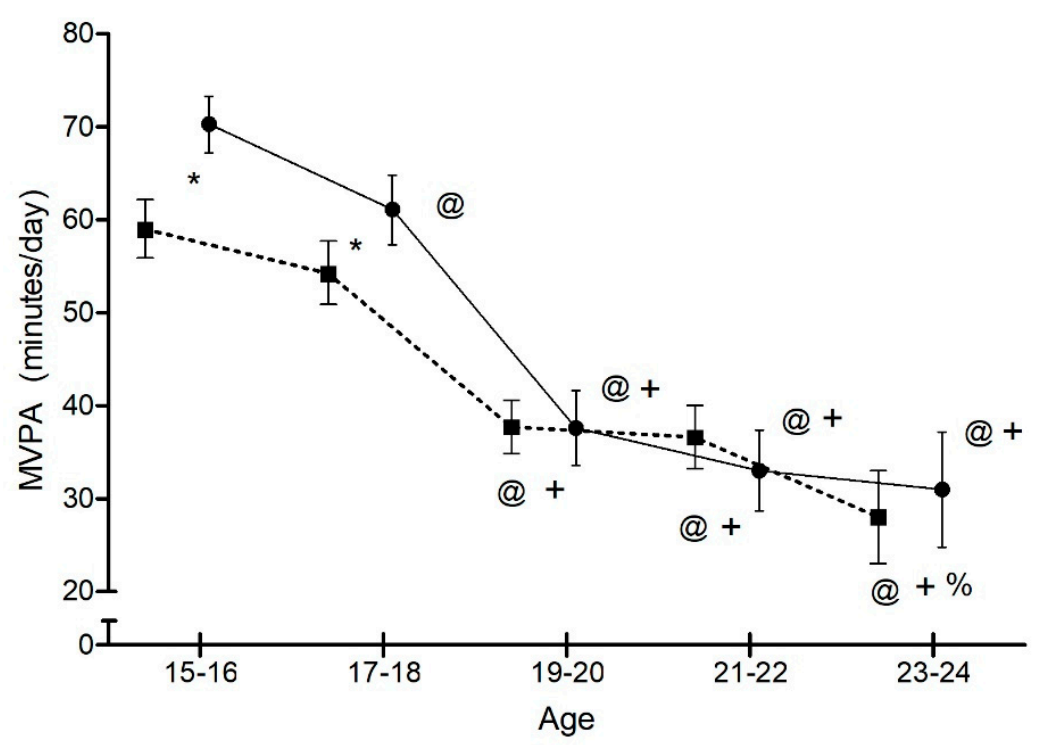

Figure 1. MVPA (in minutes/day) for men (in circles) and women (in squares) Spanish adolescents and young adults during the ages $15-24(n=7827)$. Data are means $\pm 95 \%$ confidence interval $(\mathrm{CI})$. @: Significantly different from the 15-16 year old group. +: Significantly different from the 17-18 year old group. \%: Significantly different from the 19-20 year old group. *: Significant differences between genders for a particular age.

\section{Discussion}

Our study showed a reduction of the MVPA performed from adolescence to young adulthood in a Spanish population sample. This reduction was gender-dependent, with girls reducing their PA levels at a different age and pace in adolescence and young adulthood in comparison to boys. Though there were differences in the MVPA performed between boys and girls during the 15-18 year age range, this difference was no longer significant after 18 years old. As a consequence of this, and considering all of the 15-24 year age range, reductions in men were higher than in women.

Our findings agree with the literature, in which most of the longitudinal studies show reductions in total PA with age for the whole sample and for both men and women separately $[11-13,18]$. A recent meta-analysis analyzing longitudinal studies showed similar results, indicating that in a period of around three years from adolescence to young adulthood, there is a reduction of about $5 \mathrm{~min}$ on average [24]. Nevertheless, our data report higher reductions, particularly from 15 to 19 years old.

In the same way, our study also showed higher reductions in young men versus women at older ages [18]. However, contrary to other studies, differences between genders disappeared after the 15-18 
year period, reporting comparable values of MVPA performed [18]. Previous reports have shown that the magnitude of decrease in physical activity is associated with the baseline level due to a flooring effect, in which having lower PA levels means fewer opportunities for decline [5,25]. Thus, as boys have higher physical activity levels in general, this would mean greater reductions with age.

Our data report different paces of PA reduction between boys and girls. Particularly, though boys had a significant loss of MVPA minutes/day from 15-16 to 17-18 years old, this was not observed in girls. In addition, though MVPA was lower in both young men and women of 19-24 years old compared to 17-18 years old, young women also reported reductions of MVPA minutes/day during the 23-24 years old period in comparison with 19-20 years old. Since it seems that losses in MVPA occur at different moments of adolescence and young adulthood depending on the gender, policymakers should consider these particular differences in lifestyle changes while developing interventions. Thus, this indicates that the usual approach of promoting physical activity without considering the gender of the population targeted is insufficient, since each sex has a particular pace in losing MVPA.

A previous study analyzing changes in a Spanish sample showed reductions from 15 to 16 years old, with higher reductions in boys, but no further analysis with older ages [19]. Similarly to our study, boys were more active than girls, but the PA levels in boys were reduced to a greater extent than the female counterparts [19]. In addition, our analysis showed fewer minutes of MVPA in comparison with a previous study analyzing PA in adolescent Spaniards at school [26]. That study used the Spanish version of the Four-by-One-Day Recall, an interview-questionnaire categorizing individuals into four groups. In that study, Cantera-Garde and Devís-Devís [26] found that boys were more active than girls, but in contrast to other studies, PA did not decrease with age. Differences in questionnaires implemented, age of the surveyed population, and grade of urbanity between samples might explain the differences observed between studies [26].

The abrupt reduction between 17-18 years and 19-20 years old indicates an intense social shift with significant life events happening, in which studying, working, relationships, and other types of leisure opportunities have a role [14]. In this regard, differences in commitments and mental maturation would lead girls to abandon organized PA at a younger age than men. In addition, two educational and societal changes might be very important for the adolescents and young adults in Spain, affecting their lifestyles and, thus, potentially affecting their PA behaviors: On the one hand, there are changes from the third and fourth courses of the Spanish Compulsory Secondary Education (15-16 years old) to the last two years of high school (first and second courses of the Spanish Bachillerato); on the other hand, there are changes from high school to university, vocational training, or work. These likely changes in lifestyle are the consequences of changes in the social and physical environments, opportunities to be physically active, and new commitments; all of these influence the behavior of the individual.

Descriptively, just less than half of the adolescents would fulfill the PA recommendations of $60 \mathrm{~min}$ per day by the Spanish government and international organizations such as the WHO, while most of the young adults would achieve $30 \mathrm{~min}$ per day (i.e., around $150 \mathrm{~min} /$ week) [20]. This is in line with general reports regarding PA at those ages [10,21,27]. Policymakers should consider this age range of 15-19 years for promoting interventions aimed to tackle the reduction in physical inactivity as a consequence of changes of roles, such as dropping out from organized PA such as sports or promoting active environments to engage in a more active lifestyle [10]. In this regard, considering that such levels and the progressive loss of PA are different between genders and ages, well-defined interventions should be tailored considering those two factors.

This study is not without limitations. The different ways of analyzing reported data (i.e., different questionnaires) limit the comparability with other samples and studies, suggesting carefulness in the interpretation of the findings. Additionally, we implemented a cross-sectional analysis considering the age of the surveyed population instead of performing a longitudinal analysis. While we do not believe that our type of analysis would affect the findings, extrapolation is limited. Lastly, differences in socio-economic status [7] and meteorological conditions [28] might explain differences between our study and previous analyses. Futures studies should consider these issues while analyzing the changes 
in PA levels, using standardized tools recommended by the WHO, reaching populations with dissimilar socio-economic backgrounds, and surveying during the same season of the year.

\section{Conclusions}

In a sample of the Spanish population, the MVPA performed from adolescence to young adulthood was reduced. Girls reduce MVPA at a different age and pace in adolescence and young adulthood in comparison to boys. In addition, though during the 15-18 years age range, girls were less active than boys, these differences stop existing after 18 years old. As a consequence of these dissimilar reductions in MVPA, gender-sensible policy approaches are needed to consider the lifestyle changes of a particular gender at different ages, between girls and boys, and between young women and young men.

Author Contributions: Conceptualization, X.M., A.L.-C., A.J., and F.d.V.; methodology, X.M. and A.L.-C.; software, X.M. and A.L.-C.; validation, X.M. and A.L.-C.; formal analysis, X.M., A.L.-C., A.J., and F.d.V.; investigation, X.M. and A.L.-C.; resources, X.M., A.L.-C., A.J., and F.d.V.; data curation, X.M. and A.L.-C.; writing-original draft preparation, X.M., A.L.-C., A.J., and F.d.V.; writing-review and editing, X.M., A.L.-C., A.J., and F.d.V.; visualization, X.M. and A.L.-C.; supervision, A.J. and F.d.V.; project administration, A.J. and F.d.V.; funding acquisition, A.J. and F.d.V. All authors have read and agreed to the published version of the manuscript.

Funding: This research received external funding from the MAPFRE Foundation Competitive Research Grants Support Program. Funding was allocated for the purpose of this study to the Center for Sport Studies at King Juan Carlos University.

Conflicts of Interest: The authors declare no conflict of interest.

\section{References}

1. Wu, X.Y.; Zhuang, L.H.; Li, W.; Guo, H.W.; Zhang, J.H.; Zhao, Y.K.; Hu, J.W.; Gao, Q.Q.; Luo, S.; Ohinmaa, A.; et al. The influence of physical activity, sedentary behavior on health-related quality of life among the general population of children and adolescents: A systematic review. Qual. Life Res. 2019, 28, 1989-2015. [CrossRef] [PubMed]

2. Hallal, P.C.; Victora, C.G.; Azevedo, M.R.; Wells, J.C.K. Adolescent physical activity and health: A systematic review. Sports Med. 2006, 36, 1019-1030. [CrossRef] [PubMed]

3. Telama, R.; Yang, X.; Viikari, J.; Välimäki, I.; Wanne, O.; Raitakari, O. Physical activity from childhood to adulthood: A 21-year tracking study. Am. J. Prev. Med. 2005, 28, 267-273. [CrossRef] [PubMed]

4. Telama, R.; Yang, X.; Laakso, L.; Viikari, J. Physical Activity in Childhood and Adolescence as Predictor of Physical Activity in Young Adulthood. Am. J. Prev. Med. 1997, 13, 317-323. [CrossRef]

5. Dumith, S.C.; Gigante, D.P.; Domingues, M.R.; Kohl, H.W. Physical activity change during adolescence: A systematic review and a pooled analysis. Int. J. Epidemiol. 2011, 40, 685-698. [CrossRef]

6. World Health Organization. Global Action Plan on Physical Activity 2018-2030; World Health Organization: Geneva, Switzerland, 2018; ISBN 9789241599979.

7. Guthold, R.; Stevens, G.A.; Riley, L.M.; Bull, F.C. Global trends in insufficient physical activity among adolescents: A pooled analysis of 298 population-based surveys with 1.6 million participants. Lancet Child Adolesc. Heal 2020, 4, 23-35. [CrossRef]

8. Guthold, R.; Stevens, G.A.; Riley, L.M.; Bull, F.C. Worldwide trends in insufficient physical activity from 2001 to 2016: A pooled analysis of 358 population-based surveys with 1.9 million participants. Lancet Glob. Health 2018, 6, e1077-e1086. [CrossRef]

9. Aubert, S.; Barnes, J.D.; Abdeta, C.; Nader, P.A.; Adeniyi, A.F.; Aguilar-Farias, N.; Tenesaca, D.S.A.; Bhawra, J.; Brazo-Sayavera, J.; Cardon, G.; et al. Global Matrix 3.0 physical activity Report Card grades for children and youth: Results and analysis from 49 countries. J. Phys. Act. Health 2018, 15, S251-S273. [CrossRef]

10. Roman-Viñas, B.; Marin, J.; Sánchez-López, M.; Aznar, S.; Leis, R.; Aparicio-Ugarriza, R.; Schroder, H.; Ortiz-Moncada, R.; Vicente, G.; González-Gross, M.; et al. Results from Spain's 2018 report card on physical activity for children and youth. J. Phys. Act. Health 2016, 13, S279-S283. [CrossRef]

11. Brooke, H.L.; Corder, K.; Griffin, S.J.; Van Sluijs, E.M.F. Physical activity maintenance in the transition to adolescence: A longitudinal study of the roles of sport and lifestyle activities in British youth. PLoS ONE 2014, 9, e89028. [CrossRef] 
12. Van Mechelen, W.; Twisk, J.; Post, B. Physical activity of young people: The Amsterdam Longitudinal Growth and Physical activity of young people: The Amsterdam Longitudinal Growth and Health Study Amsterdam Longitudinal Growth and Health Study. Med. Sci. Sports Exerc. 2000, 32, 1610-1616. [CrossRef] [PubMed]

13. Sallis, J.F. Epidemiology of Physical Activity and Fitness in Children and Adolescents. Crit. Rev. Food Sci. Nutr. 1993, 33, 403-408. [CrossRef] [PubMed]

14. Jose, K.A.; Blizzard, L.; Dwyer, T.; McKercher, C.; Venn, A.J. Childhood and adolescent predictors of leisure time physical activity during the transition from adolescence to adulthood: A population based cohort study. Int. J. Behav. Nutr. Phys. Act. 2011, 8, 54. [CrossRef] [PubMed]

15. Eime, R.M.; Harvey, J.T.; Sawyer, N.A.; Craike, M.J.; Symons, C.M.; Payne, W.R. Changes in sport and physical activity participation for adolescent females: A longitudinal study. BMC Public Health 2016, 16, 533. [CrossRef] [PubMed]

16. Luque Casado, A.; del Villar Álvarez, F. Mujer Joven y Actividad Física; Fundación MAPFRE: Madrid, Spain, 2019.

17. Dovey, S.M. Continuity and change in sporting and leisure time physical activities during adolescence. Br. J. Sports Med. 1998, 32, 53-57. [CrossRef] [PubMed]

18. Anderssen, N.; Wold, B.; Torsheim, T. Tracking of physical activity in adolescence. Res. Q. Exerc. Sport 2005, 76, 119-129. [CrossRef]

19. Benítez-Porres, J.; Alvero-Cruz, J.R.; De Albornoz, M.C.; Correas-Gómez, L.; Barrera-Expósito, J.; Dorado-Guzmán, M.; Moore, J.B.; Carnero, E.A. The influence of 2-year changes in physical activity, maturation, and nutrition on adiposity in adolescent youth. PLoS ONE 2016, 11, e0162395. [CrossRef]

20. World Health Organization. Global Recommendations on Physical Activity for Health; World Health Organization: Geneva, Switzerland, 2010.

21. Mayo, X.; Liguori, G.; Iglesias-Soler, E.; Copeland, R.J.; Clavel San Emeterio, I.; Lowe, A.; Del Villar, F.; Jimenez, A. The active living gender's gap challenge: 2013-2017 Eurobarometers physical inactivity data show constant higher prevalence in women with no progress towards global reduction goals. BMC Public Health 2019, 19, 1677. [CrossRef]

22. International Physical Activity Questionnaire. Guidelines for Data Processing and Analysis of the International Physical Activity Questionnaire (IPAQ)—Short and Long Forms; IPAQ Group, 2005.

23. Mayo, X.; Del Villar, F.; Iglesias-Soler, E.; Liguori, G.; Mann, S.; Jimenez, A. A retrospective analysis of policy development on compliance with World Health Organization's physical activity recommendations between 2002 and 2005 in European Union adults: Closing the gap between research and policy. BMC Public Health 2018, 18, 1081. [CrossRef]

24. Corder, K.; Winpenny, E.; Love, R.; Brown, H.E.; White, M.; Sluijs, E. Van Change in physical activity from adolescence to early adulthood: A systematic review and meta-analysis of longitudinal cohort studies. Br. J. Sports Med. 2019, 53, 496-503. [CrossRef]

25. Collings, P.J.; Wijndaele, K.; Corder, K.; Westgate, K.; Ridgway, C.L.; Sharp, S.J.; Atkin, A.J.; Stephen, A.M.; Bamber, D.; Goodyer, I.; et al. Objectively measured physical activity and longitudinal changes in adolescent body fatness: An observational cohort study. Pediatr. Obes. 2016, 11, 107-114. [CrossRef] [PubMed]

26. Cantera-Garde, M.A.; Devís-Devís, J. Physical Activity Levels of Secondary School Spanish Adolescents. Eur. J. Phys. Educ. 2000, 5, 28-44. [CrossRef]

27. European Commission; World Health Organization Regional Office for Europe. Spain: Physical Activity Factsheet; European Commission; World Health Organization Regional Office for Europe: Copenhagen, Denmark, 2018.

28. Beghin, L.; Vanhelst, J.; Drumez, E.; Migueles, J.; Manios, Y.; Moreno, L.A.; De Henauw, S.; Gottrand, F. Influence of meteorological conditions on physical activity in adolescents. J. Epidemiol. Community Health 2020, 74, 395-400. [CrossRef] [PubMed]

(C) 2020 by the authors. Licensee MDPI, Basel, Switzerland. This article is an open access article distributed under the terms and conditions of the Creative Commons Attribution (CC BY) license (http://creativecommons.org/licenses/by/4.0/). 